\title{
Prevalence of caries and developmental defects of enamel in 9-10 year old children living in areas in Brazil with differing water fluoride histories
}

\author{
E. L. Dini, ${ }^{1}$ R. D. Holt, ${ }^{2}$ and R. Bedi, ${ }^{3}$
}

\begin{abstract}
Aims To assess the prevalences of caries, of developmental defects of enamel and their interrelationship in Brazilian 9-10-year-olds from areas of contrasting fluoridation histories. Methods Systematic random sampling procedures were used to select children from an area where water had been fluoridated in 1963 and from a second area where water had been fluoridated since 1998. Clinical examinations for caries were carried out using the DMFT index and WHO diagnostic criteria.

Developmental defects of enamel on upper incisors were diagnosed using the DDE index.

Results A difference of $40 \%$ in DMFT was observed, with a lower prevalence of disease in the area fluoridated since 1963. Diffuse opacities affected $14.3 \%$ of the children from the area fluoridated since 1963 compared with only $2.4 \%$ in the area fluoridated in 1998. Children living in the area fluoridated in 1963 who had diffuse defects had twice the chance of being free from caries compared with those living in the same area who had no defects or who had only demarcated or hypoplastic defects.

Conclusions This study confirms previous ones in showing the benefits of water fluoridation. Diffuse opacities of upper incisors affected relatively few subjects in either of the two areas.
\end{abstract}

\footnotetext{
Tregularities and abnormalities of dental enamel have been associated with a very wide spectrum of aetiological factors including systemic, genetic, local and environmental conditions. Studies have shown that the prevalence of children with teeth affected by enamel defects increases in the presence of increased exposure to fluoride. ${ }^{1-5}$ In the great majority of cases and in the absence of very high levels of water fluoride these are very mild in nature.

Knowledge of the epidemiology of enamel defects is important in order to provide basic information within a community or country and between countries. It is also important since it may contribute to the assessment and monitoring of environmental or systemic factors and to detecting possible aetiological factors responsible for the occurrence of the enamel defects.

Uniformity and standardisation of methodology and reporting data in order to permit valid comparisons is essential. A variety of

${ }^{1}$ Senior Lecturer, Universidade Estadual Paulista, PO Box 331, Araraquara, SP,

Brazil $2^{*}$ Senior Lecturer, ${ }^{3}$ Head of Department, Eastman Dental Institute for

Oral Health Care Sciences, 256 Gray's Inn Road, London WC1X 8LD

${ }^{*}$ Correspondence to: $R$. Holt

REFEREED PAPER

Received 21.06.99; accepted 12.11.99

(c) British Dental Journal 2000; 188: 146-149
}

indices have been introduced to measure enamel defects. Some of these rest on the assumption that defects resulting from excessive fluoride intake may be differentiated clinically but others are purely descriptive. The FDI World Dental Federation introduced a descriptive index, the Developmental Defects of Enamel index (DDE index). ${ }^{6}$ In its original form this proved cumbersome and difficult to use and a modified version was subsequently introduced. ${ }^{7}$ This has been increasingly adopted over the past decade, facilitating comparisons between studies. ${ }^{1,3,5,8-12}$

Several studies have been particularly focused on maxillary central incisors. These are believed to be the most commonly affected teeth and also those in which defects have the greatest cosmetic impact. Child prevalences of defects have ranged from $19 \%$ to $45 \% .^{1,9,13-15}$

The effect of fluoridation of water supplies on the prevalence of enamel defects has been studied. Results in a review of studies carried out in the United Kingdom since 1956 suggested that the prevalence of developmental defects in general and of fluorosis in particular had increased not only in optimally fluoridated areas but also in those which were fluoride deficient. ${ }^{18}$ Other causes have been sought and studies using multivariate analysis have shown an association between fluorosis and a diversity of variables including toothpaste use, fluoride supplement use, frequency of brushing, social class, ethnicity, breast feeding and medical and dental histories. ${ }^{19-25}$

Fluoride use provides major benefit in reducing caries and the relationship between enamel defects and dental caries has been studied more than once. Results of these studies have so far been consistent in showing an inverse relationship between caries and diffuse enamel opacities. ${ }^{1,11,25}$ However the majority of studies of developmental defects of enamel have been confined to North America, Australia and European countries. To date there has been little study of these defects or of their relationship to caries in children in less developed countries such as Brazil.

The aim of this study is therefore to assess the prevalence and patterns of dental caries and the prevalence of developmental defects of enamel and the association, if any, between these in Brazilian schoolchildren aged 9-10 years living in areas with different levels of fluoride in the drinking water.

\section{Material and methods}

Population and sampling

The population for this study consisted of school children aged 9-10 years in 1998. The children were continuous residents enrolled in state maintained schools in the cities of Araraquara 
and Américo Brasiliense, in the State of São Paulo, Brazil. The city of Araraquara has been fluoridated since 1963 (0.7 ppm F) and part of the water supply of the city of Américo Brasiliense has been fluoridated since the beginning of 1998. The socio-economic conditions and the ethnic profile of the population in the two cities are similar. Approval for the study was given by the Secretary of Education and the Coordinators of the Municipal Dental Services from both areas. Clinical examinations are carried out every year in the schools and are part of routine programmes. Written consent to examination is given by the mothers of children enrolled in the schools.

Systematic random sampling procedures after stratification by age were used to select the samples for study. Sample sizes were defined according to Silva, ${ }^{26}$ with a level of significance of $5 \%$ and a level of precision in estimating caries prevalence of 0.25 . The variances used in the estimations were those obtained in the last epidemiological survey carried out in Araraquara in $1995 .{ }^{27}$ A total of 287 children from Araraquara and 210 from Américo Brasiliense were included in the sample $(6.1 \%$ of the population of 9-10-year-old children enrolled in the 35 state schools in Araraquara and $19.7 \%$ of the population of 9-10year-old children enrolled in the 6 state schools in Américo Brasiliense in 1998).

\section{Clinical examinations}

Clinical examinations for recording dental caries were carried out in the schools by four examiners who had been previously trained using the DMFT index and the WHO diagnostic criteria. ${ }^{28}$ Kappa statistics were used to express the intra- and inter-examiner reliability. Intra-examiner kappa values were $\kappa=0.87 ; 0.85 ; 0.85$ and 0.91 for examiners one, two, three and four, respectively. Interexaminer kappa values ranged from 0.87 between examiners one and two, and 0.93 between examiners one and three and between examiners one and four.

Clinical examinations for recording developmental defects of enamel on upper incisors were carried out in the schools by one examiner previously trained using the modified DDE index. ${ }^{7}$ The teeth were examined in the presence of natural light. Debris was removed by wiping with a gauze square before the clinical examination where necessary. The fieldwork examiner (ELD) was trained and calibrated by a reference examiner (RDH) with the use of slides of incisor teeth of children of the same age. The kappa values between the reference examiner and the fieldwork examiner were $\kappa=0.72$ for the DDE diagnostic criteria and DDE extent. The kappa values estimated from repeat examination of slides for the intra consistency of the fieldwork examiner were $\kappa$ $=0.83$ for the DDE diagnostic criteria and $\kappa=0.78$ for the DDE extent of the defect.

\section{Data analysis}

Data was entered onto the SPSS software for analysis. A non parametric test (Mann-Whitney $U$ test) was used to compare mean DMFT values in the two areas and unpaired ' $t$ ' test was used to compare mean values only among those with caries. ${ }^{29}$ Tests of the association between the prevalence of caries and developmental defects of enamel were carried out using the chi-squared test. The $95 \%$ level of confidence was used for testing.

\section{Results}

Preliminary analyses showed no differences in the prevalence of caries and developmental defects of enamel between genders and the results were therefore combined.

Table 1 shows the prevalence of caries in the two groups of children, the patterns of caries in terms of types of teeth affected, mean DMFT and mean DMFT for those with caries. In the area fluoridated since $1963,47 \%$ of the children had experience of caries. A
Table 1 Number and percentage of 9-10-year-old children with caries, mean DMFT and mean DMFT for those with caries by tooth type affected and area of residence

\begin{tabular}{|c|c|c|}
\hline & \multicolumn{2}{|c|}{ Area of residence } \\
\hline & $\begin{array}{c}\text { Fluoridated } \\
\text { since } 1963 \\
(n=287)\end{array}$ & $\begin{array}{c}\text { Fluoridated } \\
\text { in } 1998 \\
(n=210)\end{array}$ \\
\hline Number $(\%)$ with caries & 134 (46.7) & 133 (63.3) \\
\hline Mean DMFT (SD) & $1.08(1.42)$ & $1.82(1.81)^{*}$ \\
\hline Mean DMFT (SD) for those with caries & $2.31(1.22)$ & $2.88(1.46)^{\dagger}$ \\
\hline \multicolumn{3}{|l|}{ Molars and/or premolars } \\
\hline Number $(\%)$ with caries & $133(46.3)$ & $126(60.0)$ \\
\hline Mean DMFT (SD) & $1.06(1.35)$ & $1.69(1.70) *$ \\
\hline Mean DMFT (SD) for those with caries & $2.27(1.19)$ & $2.66(1.41)^{\ddagger}$ \\
\hline \multicolumn{3}{|l|}{ Molars and incisors (and/or canines) } \\
\hline Number $(\%)$ with caries & $1(0.3)$ & $4(1.9)$ \\
\hline Mean DMFT (SD) & $0.02(0.35)$ & $0.11(0.87)$ \\
\hline Mean DMFT (SD) for those with caries & $0.04(0.52)$ & $0.17(1.09)$ \\
\hline \multicolumn{3}{|l|}{ Incisors and/or canines } \\
\hline Number $(\%)$ with caries & - & $3(1.4)$ \\
\hline Mean DMFT (SD) & - & $0.02(0.29)$ \\
\hline Mean DMFT (SD) for those with caries & - & $0.04(0.37)$ \\
\hline
\end{tabular}

${ }^{*} P=0.0001$ (Mann-Whitney $U$ test)

$\dagger P=0.001(t$-test $)$

$\ddagger P=0.014$ (ttest)

Table 2 Number and percentage (in parentheses) of 9-10-yearold children according to developmental defects of enamel on upper incisors (DDE) and area of residence

\begin{tabular}{lccc}
\hline & \multicolumn{2}{c}{ Area of residence } & \\
Fluoridated & $\begin{array}{c}\text { Fluoridated } \\
\text { since } 1963 \\
(n=287)\end{array}$ & $\begin{array}{c}\text { in 1998 } \\
(n=210)\end{array}$ & $\begin{array}{c}\text { Total } \\
(n=497)\end{array}$ \\
\hline DDE & $75(26.1)^{*}$ & $24(11.4)^{\dagger}$ & $99(19.9)$ \\
With defects & $32(11.1)$ & $20(9.5)$ & $52(10.5)$ \\
Demarcated defects & $41(14.3)$ & $5(2.4)$ & $46(9.3)$ \\
Diffuse defects & $5(1.7)$ & $1(0.5)$ & $6(1.2)$ \\
Hypoplastic defects & $212(73.9)$ & $186(88.6)$ & $398(80.1)$ \\
With no defects & $212(80.1)$ &
\end{tabular}

Note: Children who showed two types of defects in the same tooth have been classified according to which type affected the larger area of the tooth surface.

* Three children had two types of defects (demarcated and diffuse) in different teeth † Two children had two types of defects (demarcated and diffuse) in different teeth

higher proportion, $63 \%$ of those examined, were affected in the very recently fluoridated area. Statistically significant differences between the two areas were seen in the mean DMFT $(P<0.001)$ and mean DMFT for those with caries $(P<0.01)$.

In both areas nearly all the 9-10-year-old children with caries experience had disease that was confined to molars, $46 \%$ of children were affected in the area fluoridated since 1963 and 60\% in the area fluoridated in 1998.

The more extensive pattern of caries involving molars and incisors (and/or canines) and caries in incisors and/or canines was much less frequently observed in this age group affecting only 5 of the 497 children in the study (Table 1).

The prevalence of developmental defects of enamel using the DDE index and scoring upper incisors is shown in Table 2 and Figure 1 . In total the prevalence of opacities was $20 \%$ with similar prevalences of demarcated (10.5\%) and diffuse defects $(9.3 \%)$. Hypoplastic defects were observed less frequently with only $1.2 \%$ of children affected (Table 2). Developmental defects of enamel were more common in the area fluoridated since 1963. Differences were largely in diffuse opacities with these affecting $14.3 \%$ of the children compared with only $2.4 \%$ in the area fluoridated in 1998 (Fig. 1).

The prevalence of demarcated defects was similar in the two 


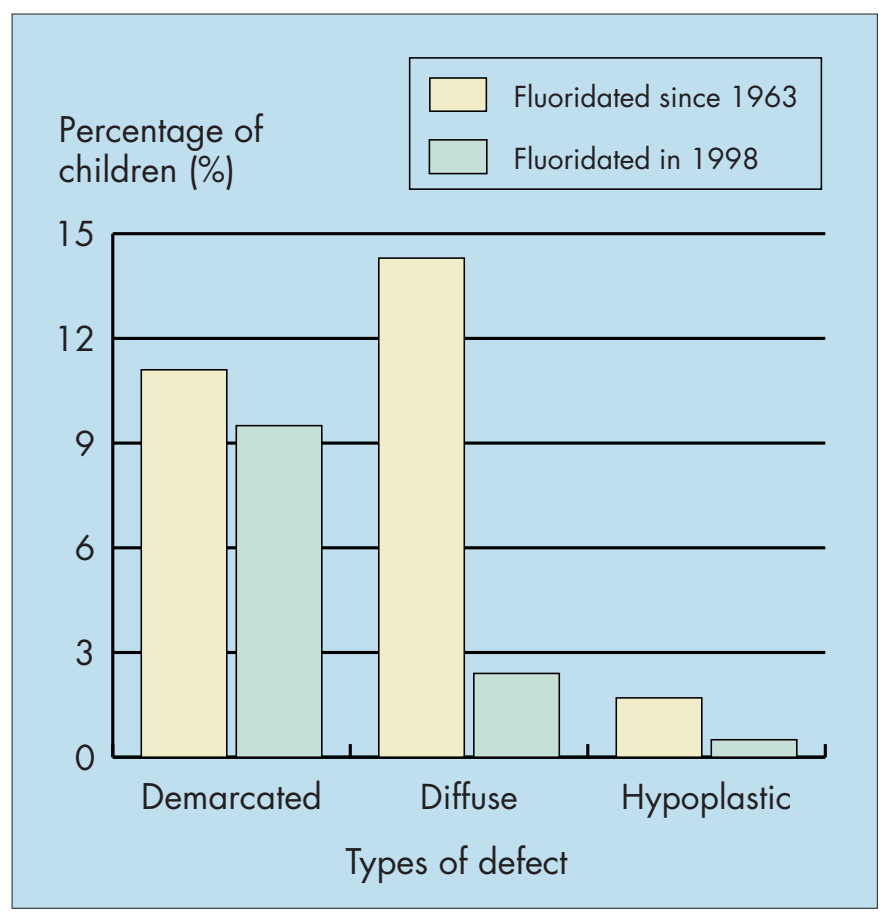

Fig. 1 Percentage of children with developmental defects of enamel according to area of residence

areas with these affecting $11.1 \%$ of the children in one area and 9.5\% in the other (Table 2 and Fig. 1).

The relationship between the prevalence of dental caries and developmental defects of enamel in the two areas is shown in Table 3. Analysis using the chi-squared test showed statistically significant differences between prevalence of dental caries and types of developmental defects of enamel $(P<0.05)$ for those children living in the area where fluoridation had been continued for longer. Estimation of the odds ratio showed that children without opacities or who had demarcated or hypoplastic defects and living in this area had twice the risk of having caries compared with those who had diffuse opacities (Table 3 ).

\section{Discussion}

Results in this study concerning prevalence of caries are in agreement with numerous other investigations in showing the benefits of water fluoridation; ${ }^{15,30-32}$ the prevalence of dental caries was lower in children living in the area where fluoridation started in 1963.

Most studies suggest, for permanent teeth, a difference of $50 \%$ to $60 \%$ in DMFT between optimally fluoridated areas and those with low fluoride levels but in the current study the difference was lower, at $40 \%$. One explanation for this may lie in the age of children studied (9-10 years). At this age, when few second molars and premolars are erupted, caries is likely to be (and was) largely confined to first permanent molars where it typically affects occlusal fissures. Occlusal fissures have been reported to show less benefit from fluorides than do either approximal or smooth tooth surfaces. ${ }^{27,33,34}$ It is of note that only eight children had caries affecting incisor teeth but of these, seven were from the area fluoridated for less than 12 months.

The prevalence of disease in the area fluoridated since 1963 was lower than in the past. ${ }^{27,35}$ It was similar to that reported recently for children from non fluoridated areas in Spain suggesting that Brazil may lag behind some countries. ${ }^{36}$ Confirmation of this fact may lie in the finding that mean DMFT values in this study were also broadly similar to those observed in children from fluoridated areas in the USA more than 10 years ago. ${ }^{37}$

The proportion of 9-10-year-olds from both areas with developmental defects of enamel was lower than the range of findings from some other studies carried out during the past decade in areas with and without fluoridated drinking water. ${ }^{18}$ Prevalences between 40 and $79 \%$ have been reported in areas with fluoridation. However, direct comparisons of results between studies need to be made with caution because of differences in the study conditions and in the index used. In this study estimates of the prevalence of developmental defects of enamel were made through clinical examination of upper incisor teeth alone and with the use of natural light; the prevalence of children affected may consequently be lower than in studies using photographs, for example, ${ }^{38,39}$ or when more teeth were included. The proportions of children recorded as having diffuse opacities who had been continuous residents in the area fluoridated since 1963 were, nevertheless, similar to those reported for children from fluoridated areas in Ireland ${ }^{3}$ but were lower than those seen in children from England where there is little fluoridation. ${ }^{21,22,40}$ The percentage of children with demarcated opacities in the current study was also lower than those reported for children of comparable age in Italy ${ }^{1}$ and Ireland. ${ }^{3}$

Studies using a variety of indices have suggested that developmental defects of enamel in general and fluorosis in particular are both more prevalent in optimally fluoridated than in fluoride-deficient areas. ${ }^{1,3,10,18}$ In measuring enamel opacities with the use of a descriptive index (such as the DDE index), no assumption is made as to aetiology. At least one previous study has shown however that similar trends may be seen with diffuse defects, using the DDE index, with a specific index for fluorosis, such as the Thylstrup and Fejerskov (TF) index. ${ }^{25}$

In the current study the prevalence of diffuse defects was higher in children living in the area where fluoridation had been contin-

\begin{tabular}{|c|c|c|c|c|}
\hline $\mathrm{DDE}^{*}$ & & Area o & idence & \\
\hline & Fluoric & since 1963 & Fluorida & n 1998 \\
\hline & $\begin{array}{l}\text { DMFT }=0 \\
(\mathrm{n}=153)\end{array}$ & $\begin{array}{l}\text { DMFT } \geq 1 \\
(n=134)\end{array}$ & $\begin{array}{c}\mathrm{DMFT}=0 \\
(\mathrm{n}=77)\end{array}$ & $\begin{array}{l}\text { DMFT } \geq 1 \\
(n=133)\end{array}$ \\
\hline $0,1,3$ & 125 (81.7) & $121(90.3)^{\dagger}$ & $76(98.7)$ & 129 (97.0) \\
\hline 2 & 28 (18.3) & $13(9.7)$ & $1(1.3)$ & $4(3.0)$ \\
\hline *DDE: & $\begin{array}{l}0=\text { no defect } \\
1=\text { Demarcated opacities } \\
2=\text { Diffuse opacities } \\
3=\text { Hypoplastic defects }\end{array}$ & $\begin{array}{c}\dagger P=0.0378 \\
\mathrm{OR}=2.1\end{array}$ & quared test) & \\
\hline
\end{tabular}

Note: For purpose of analysis using the chi-squared test, children who had demarcated and diffuse opacities in different teeth were included in the category of diffuse opacities only. 
ued for longer than in their counterparts living in the more recently fluoridated area. That these are the defects associated with fluoride may be suggested by findings that a higher prevalence of diffuse defects is associated with the use of fluoride supplements, ${ }^{5,25}$ the use of fluoride toothpaste ${ }^{25}$ and the use of fluoride dentifrices at an early age in optimally fluoridated areas. ${ }^{20,23,41,42}$

Fluoride supplements are not used in Brazil but since 1988 about $90 \%$ of commercially available dentifrices in Brazil has been fluoridated ${ }^{43}$ with most containing standard (1000 ppm) fluoride ion concentrations as directed by the Ministry of Health.

The prevalence of diffuse opacities has been shown to have a direct relationship to the proportions of children free from caries $1,11,25$ and results in the present study concur with these previous findings. Children from the optimally fluoridated area who had diffuse defects had twice the chance of being free from caries than those who had no defects or who had only demarcated or hypoplastic opacities.

The benefits of water fluoridation and of other sources of fluoride, particularly fluoridated toothpastes are widely evident throughout the world. It is important that both are used appropriately to promote oral health.

1 Angelillo I F, Romano F, Fortunato L, Montanaro D. Prevalence of dental caries and enamel defects in children living in areas with different water fluoride concentrations. Community Dent Health 1990; 7: 229-236.

2 Burt B A. The changing patterns of systemic fluoride intake. J Dent Res 1992; 71: 1228-1237.

3 Clarkson J J, O'Mullane D M. Prevalence of enamel defects/fluorosis in fluoridated and non-fluoridated areas in Ireland. Community Dent Oral Epidemiol 1992; 20: 196-199.

4 Fomon S J, Ekstrand J. Fluoride intake. In Fejerskov O, Ekstrand J, Burt BA (eds). Fluoride in Dentistry. 2nd ed. Copenhagen: Munksgaard, 1996.

5 Hiller K-A, Wilfart G, Schmalz G. Developmental enamel defects in children with different fluoride supplementation - a follow-up study. Caries Res 1998; 32: 405-411.

6 Federation Dentaire Internationale. Commission on oral health, research and epidemiology: a review of developmental defects of enamel index (DDE Index). Int Dent J 1992; 42: 411-426.

7 Clarkson J. Review of terminology, classifications and indices of developmental defects of enamel. Adv Dent Res 1989; 3: 104-109.

8 King N M. Developmental defects of enamel in Chinese girls and boys in Hong Kong. Adv Dent Res 1989; 3: 120-125.

9 Dummer P M H, Kingdon A, Kingdon R. Prevalence and distribution by tooth type and surface of developmental defects of dental enamel in a group of 15-to 16-year-old children in South Wales. Community Dent Oral Epidemiol 1990; 7:360-377.

10 Nunn J H, Ekanayake L, Rugg-Gunn A J, Saparamadu K D G. Distribution of developmental defects of enamel on ten tooth surfaces in children aged 12 years living in areas receiving different water fluoride levels in Sri Lanka and England. Community Dent Health 1993; 10: 259-268.

11 Downer M C, Blinkhorn AS, Holt R D, Wight C, Attwood D. Dental caries experience and defects of dental enamel among 12-year-old children in North London, Edinburgh, Glasgow and Dublin. Community Dent Oral Epidemiol 1994; 22: 283-285.

12 Seow W K, Amaratunge A, Bennett R, Bronsch D, Lai P Y. Dental health of aboriginal pre-school children in Brisbane, Australia. Community Dent Oral Epidemiol 1996; 24: 187-190.

13 Murray J J, Shaw L. Classification and prevalence of enamel opacities in human deciduous and permanent dentition. Arch Oral Biol 1979; 24: 7-12.

14 Suckling G W, Pearce E I F. Developmental defects of enamel in a group of New Zealand children. Community Dent Oral Epidemiol 1984; 12: 177-184.

15 Murray J J, Rugg-Gunn A J, Jenkins G N. Fluorides in caries prevention. 3rd ed. Oxford: John Wright, 1991.

16 Forrest J R, James P M C. A blind study of enamel opacities and dental caries prevalence after eight years of fluoridation of water. Br Dent J 1965; 119: $319-322$
17 Murray J J, Gordon P H, Carmichael C L, French A D, Furness J A. Dental caries and enamel opacities in 10-year-old children in Newcastle and Northumberland. Br Dent J 1984; 156: 255-258.

18 Holloway P J, Ellwood R P. The prevalence, causes and cosmetic importance of dental fluorosis in the United Kingdom: a review. Community Dent Health 1997; 14: 148-155.

19 Szpunar S M, Burt B A. Dental caries, fluorosis and fluoride exposure in Michigan schoolchildren. J Dent Res 1988; 67: 802-806.

20 Pendrys D G, Katz R V. Risk of enamel fluorosis associated with fluoride supplementation, infant formula and fluoride dentifrice use. Am J Epidemiol 1989; 130: 1199-1208.

21 Milsom K, Mitropoulos C M. Enamel defects in 8-year-old children in fluoridated and non-fluoridated parts of Cheshire. Caries Res 1990; 24: 286-289.

22 Hamdan M, Rock W P. The prevalence of enamel mottling on incisor teeth in optimal fluoride and low-fluoride communities in England. Community Dent Health 1991; 8: 111-119.

23 Riordan P J. Dental fluorosis, dental caries and fluoride exposure among 7year-olds. Caries Res 1993; 27: 71-77.

24 Elwood R P, O’Mullane D M. The demographic and social variation in the prevalence of dental enamel opacities in North Wales. Community Dent Health 1994; 11: 192-196.

25 Holt R D, Morris C E, Winter G B, Downer M C. Enamel opacities and dental caries in children who used a low fluoride toothpaste between 2 and 5 years of age. Int Dent J 1994; 44: 331-341.

26 Silva E P C. Amostragem. São Paulo: Faculdade de Saúde Pública, 1968.

27 Dini E L, Holt R D, Bedi R. Prevalence and severity of caries in 3-12-yearold children from three districts with different fluoridation histories in Araraquara, SP, Brazil. Community Dent Health 1998; 15: 44-48.

28 World Health Organization. Oral health surveys. Basic methods. 3rd ed. Geneva: WHO, 1987.

29 Bulman J S, Osborn J O. Statistics in Dentistry. London: British Dental Association, 1989.

30 Newbrun E. The effectiveness of water fluoridation. J Publ Health Dent 1989; 49(Spec Iss): 279-289.

31 Lewis D W, Banting D W. Water fluoridation: current effectiveness and dental fluorosis. Community Dent Oral Epidemiol 1994; 22: 153-158.

32 Spencer A J, Slade G D, Davies M. Water fluoridation in Australia. Community Dent Health 1996; 13: 27-37.

33 Jackson D, Sutcliffe P. Clinical testing of a stannous fluoride-calcium pyrophosphate dentifrice in Yorkshire schoolchildren. Br Dent J 1967; 123: 40-48.

34 Hargreaves J A, Chester C G, Wagg B J. Assessment of children in active and placebo groups one year after termination of a clinical trial of a $2 \%$ sodium monofluorophosphate dentifrice. Caries Res 1975; 9: 291.

35 Dini E L, Foschini A L R, Mendonça F C C, Nardo G, Abbade M T G, Frais RLMS. Changes in dental caries prevalence of school children in Araraquara, SP, Brazil. Int Dent J 1996; 46: 82-85.

36 Alvarez-Arenal A, Alvarez-Riesgo J A, Pena-Lopez J M, Fernandez-Vasquez J P. DMFT, dmft and treatment requirements of schoolchildren in Asturias, Spain. Community Dent Oral Epidemiol 1998; 26: 166-169.

37 Hinman A R, Sterritt G R, Reeves T G. The US experience with fluoridation. Community Dent Health 1996; 13(Suppl 2): 5-9.

38 Levine R S, Beal J F, Fleming C M. A photographically recorded assessment of enamel hypoplasia in fluoridated and nonfluoridated areas in England. Br Dent J 1989; 166: 249-252.

39 Nunn J H, Murray J J, Reynolds P, Tabari D, Breckon J. The prevalence of developmental defects of enamel in 15-16 year old children residing in three districts (natural fluoride, adjusted fluoride, low fluoride) in the North East of England. Community Dent Health 1992; 9: 235-247.

40 Ellwood R P, O’Mullane D M. Dental enamel opacities in three groups with varying levels of fluoride in their drinking water. Caries Res 1995; 29: 137142.

41 Osuji O O, Leake J L, Chipman M L, Nikiforuk G, Locker D, Levine N. Risk factors for dental fluorosis in a fluoridated community. J Dent Res 1988; 67: 1488-1492.

42 Pendrys D G. Risk of fluorosis in a fluoridated population. JAm Dent Ass 1995; 126: 1617-1624.

43 Cury J A. Uso de flúor. In Baratieri LN et al. Dentística: procedimentos preventivos e restauradores. São Paulo: Quintessence, 1989. 